\title{
Commercial Value and service innovation management of Lahos elders in the Internet age
}

\author{
Author: Mingxiao Zhao ${ }^{1}$ \\ ${ }^{1}$ Industrial and Commercial Management Department, Dalian Vocational and Technical College, Dalian, China
}

\begin{abstract}
Lahos elders are outperformers among the old population, featuring good physical conditions, new ideas and strong consumption power. In the Internet age, Lahos elders boast tremendous market potential, and it is a focus of the old age market to grasp the market opportunities, explore consumption features, enrich the content of services and innovate on the service management modes. Lahos elders have large consumption needs, set store by socializing activities, and pursue quality in consumption. Innovative services that are characterized by mutual help, convenience, enrichment, education and sharing will become a dominating trend of the old age market.
\end{abstract}

\section{INTRODUCTION}

As defined by the World Health Organization, people aged above 65 are defined as elders, and in China, people above 60 years old are regarded as old persons. With economic and social advancement, the lifespan extends, and people's educational level improves. The aged are no longer by words of aging, illness, kitchen keepers or children minders; instead, they bear new labels including travelling, health preservation, socializing, work, having both time and money, energy and optimism. The new generation of old people are called "Lahos elders". The Internet empowers the Lahos elders, providing them with more channels to realize their commercial value and more chances for commercial services and help.

\section{Commercial values of Lahos elders in the Internet age}

\subsection{Economic volume of the Lahos elders}

Undoubtedly, China has entered an aged society, with the aged taking up an increasing proportion in the whole population. As of 2019, peopled aged above 65 in China reached 176.03 million, an increase of 9.45 million from 2018, accounting for $12.6 \%$ of the whole population, which means a $0.7 \%$ increase than 2018 [1].

As the new-generation old people increase, the education makeup of the old population changes: more old people have completed high school, and have not gone through harsh times throughout their life; they are full of modern ideas about old life, enjoy fit-keeping, have high standards and plans for their life in their old ages. As the major force in the aged population, the Lahos elders are taking up an increasing proportion.

\subsection{Consumption of the Lahos elders boosted by e-shopping}

The Lahos elders have much time to while away, stable pension and some savings. They no longer need to worry about their kids who have already been adults and have much leisure time after retirement. They demand high life standards, never deny themselves of enjoyments, and want to lead a happy life and make up for past regrets through shopping.

A report released by China National Committee on Ageing suggests that the old age market in China would reach a volume of 3.79 trillion yuan in 2020[2]. AgeClub is an organization committed to research on the old age market. In 2019, the organization made an investigation with old people aged between 50 and 60 in Beijing as the targets. The result revealed that $75 \%$ of the old people investigated spent an average of above 500 yuan on eshopping, and $60 \%$ of them would shop online above three times; more than $52 \%$ of them bought $2-4$ shoes per year, and the price of the shoes ranged from 300 to 500 [3].

\subsection{Internet boosting the impact of the consumption of the Lahos elders}

The elders are usually susceptible to the influence of the young in consumption behaviors and they tend to believe the experience of those nearby. They are optimistic and keen on socializing events. They have organized various types of chat groups, both online and offline, including colleagues, classmates, and other hobby groups; they love to share their experience in daily communication and casual chats. They are never shy form voicing their 
opinions in WeChat moments, and love to share their shopping experience to help others. Their consumption habits often have a large influence on others'.

\subsection{Re-employment of Lahos elders constituting a new commercial force}

Recent years have seen more elders returning to the workplace and growing into a new force of business. Many elders continue working after retirement and some even start their own businesses. Compared with young entrepreneurs, they do not need to concern about capital, and have an edge over their younger counterparts in capacity, social network and social resources. Old entrepreneurs aside, most elders turn to business services that fall within their capacity. Compared with the young, they cherish the chance for work, and value the sense of fulfillment brought by the job more than the incentives like promotion. Many old people return to the workplace by serving as child minders, which relieve their work pressure and add to their self-value, and thus can be taken as a form of re-employment.

\section{CONSUMPTION FEATURES OF LAHOS ELDERS}

\subsection{More needs for socializing than for consumption}

\subsection{1 the large proportion of the old that live alone}

Most old people now have less children than before, and their children are pursuing study and work in cities far away from their parents, and most of them enjoy living alone. Because of these reasons, seldom old people live with their young children, and most live in different regions even in the same city. In 2016, the 4th sampling investigation of living conditions of Chinese old people revealed that "empty nesters" (old couples living alone or bereaved old people living alone) took up 51.3\% of the old population nationwide [4].

\subsubsection{Lahos elders valuing sentimental experience in consumption}

Lahos elders are fashion leaders among the old people. They are the most active in communities, love to help others and friend with neighbors, communicate with others during travelling, community events, strolls and shopping errands. As intelligent devices gain popularity, Lahos elders are moving online, and the diverse WeChat moments provide more channels to socialize and share emotions for them. A research report shows that many aged users of Pingduoduo (an e-commerce platform) has no e-shopping habits before. Because of the group bargaining and group shopping discounts the platform offers, they are attracted and move from offline to online.

\subsubsection{The consumption content easily influenced by the group}

The socializing needs of the elders make them to hang out with friends of different types, with diverse contents for communication. Their social circle is stable, and members of circle are likely to follow others and generate group consumption behaviors. The rage of health products among the aged in the past is because the aged love following the trend and are easily taken advantage of their emotional needs.

The old people, under the influence of their friends, develop mature consumption ideas and begin to consume products for the old - travel, cosmetics, health products, skills training programs, entertainment programs, etc. Gradually, they develop a scientific knowledge of the products' features, the brand quality and the use specifications.

\subsection{Diversity of products for Lahos elders}

As the social network of Lahos elders expands and the Internet gains popularity, their horizon expands, and the products they consume improve and expand. Aside from daily supplies, they are consuming new products like fitkeeping programs, travelling, health preservation programs, entertainment and study projects, etc.

Health products are the major content of consumption of the Lahos elders, including regular physical checks, medical care services, drugs and health products, as well as dietary guidance. Lahos elders enjoy fit-keeping, and thereby boost consumption of gym suits, gym equipment and equipment.

Travelling also accounts for a major content of consumption among the Lahos elders. In the National Day Festival in 2019, more than 700 million people went travelling, and the post-1950s are the most spendthrift, spending an average of 3640 yuan per person per trip [5]. Many Lahos organized health preservation short trips like hot spring trips and physiotherapies; some who enjoy outings also went cycling and self-guided trips.

Lahos elders have diverse entertainment and study activities, from square dancing to universities for the old, from basic skills to higher education. They are make up for the skills that they failed to develop when they were young; with the development of Internet, the entertainment programs of the Lahos elders move from offline to mobile phones, and many elders have become snappy Internet users.

\subsection{Lahos elders pursuing higher quality of life}

Innovations Lahos elders are not frugal elders who "prefer saving to spending”. Born after the founding of China, they have received much education and have developed modern consumption habits. They have high standards for their late life, and with their life experience and stable income, they have a clear idea of their consumption capacity and are willing to improve their life quality through consumption. 
The large amounts of money the Lahos elders spend on health products are not the only manifestation of their high quality consumption. More elders prefer investing in their hobbies, and more elders are joining in universities for the old. The travelling market for the old no longer just provides "shoestring" budget travelling programs; rather, they are providing more quality and entertaining programs. Lahos elders pay more attention to health products; as for cosmetics, 95\% of old women do makeups and prefer high-end cosmetic products. They want to spoil themselves in old ages. Experts say that the upgrading of consumption of elders has come.

\subsection{Lahos elders spending mainly offline, with e-shopping being a supplement}

Due to the physical conditions of the aged, they need to move around every day for health purposes, so most of them would go shopping, especially for daily supplies, in person, which is a form of relax and exercise. As a result, the malls and supermarkets become major venues for their consumption. In particular, as their needs for socializing increase and because of their habits of chatting while shopping, they tend to shop in a fixed mall or familiar places.

As Internet-savvy Lahos elders grow in number, more mobile shopping apps come into being. The report by AgeClub further confirms that most Lahos elders go shopping in concrete-and-mortar shops, but move gradually to online venues via WeChat and e-commerce platforms (Figure 1).

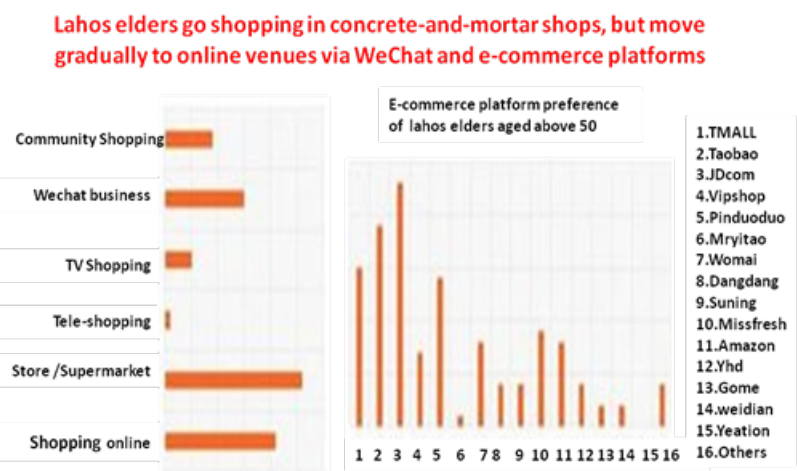

Figure 1. Shopping venues of high-value Lahos elders aged above 50

\section{INNOVATION OF SERVICES FOR LAHOS ELDERS IN THE INTERNET AGE}

\subsection{Adjacency-oriented services}

Adjacency-oriented services first indicate geographical proximity. The service providing venues should be close to the Lahos elders, easily accessible by the elders, and cater to the elders' habits of shopping nearby so that the elders can integrate shopping, exercising, and socializing. Adjacency-oriented services also demand emotional closeness. The service providers should be close to the elders in emotions, meet their emotional needs, extend care to their daily life, provide VIP services and establish a stable customer relationship.

Adjacency-oriented services provide a grand market niche for community business and community elderlycare services. In recent years, the rate of repeated shopping of Lahos elders in nearby shopping malls increases. The malls are spacious, have areas for rest, and are not subject to influence of weather. Thus, they become optimal venues for elders to take a walk while shopping and enjoying catering services.

\subsection{Sharing services}

Sharing services meet the cultural and social needs of the Lahos elders. They enjoy chatting and love gathering, so experience and sharing business programs can increase the commercial value of Lahos elders.

By sharing-style promotion campaigns, such as earning points by forwarding on WeChat, group travelling, or offline elder chatting parties, business owners can appeal to the elders in various ways. "Fandeng Classroom for the aged" is a successful sharing service that provides an intellectual, enjoyable and valuable learning and socializing venue for the aged; there, the elders with same hobbies can learn, socialize, communicate and develop friendship with each other.

\subsection{Mutual-help services}

Mutual-help services refer to a mode in which the elders help each other by dint of their specific physical strength, experience, and knowledge. In "Principles for Older Persons" released by the UN in 1991, the 46th resolution includes five principles, in which the principles for "involvement" means that the old persons are supposed to seek chances to serve the society and volunteer in events that they are interested in or suit their capacity.

The old persons used to be considered as disadvantaged groups that need care and attention; as the society moves forward, however, many elders are still in form both in terms of physical strength and professional skills, and therefore can help others. Lahos elders are more salient among the old persons because their modern ideas of old life make them more willing to take part in social services. As early as in September 2016, Xiufeng District in Guilin city launched a mutual-help care for the aged volunteer program, which made full use of the resources in community, enriched the content of services for the aged, and realized mutual help among the aged.

\subsection{Educational services}

The aged are entering a new stage of life that they need to adapt themselves to, to start afresh, to handle all daily trivia. A healthy and meaningful old life requires learning. Consumption campaigns blinded planned for the aged, such as health products, cheap traveling groups, etc., hurt the old people. Most old persons do not know how to protect their lawful rights, and as they age, their judgement and logic are no longer as astute as used to be. Thus, the service mode for the aged should make full use 
of the professional advantages of the service providers, organize on-site service or other campaigns to promote correct ideas of consumption, provide educational services, help the aged contribute to consumption in a reasonable and correct manner.

Educational services also refer to providing guidance for the aged. By providing novel ways of consumption and life styles, the service providers can provide more options for the aged and enrich the content of services. When consuming new contents, the elders need guidance to know more about the brand and functions. For instance, the cosmetics market for the aged may enjoy a good prospect, but as many old persons do not know much about make-up products, and rely heavily on well-known brands, this market is still to be developed. In the process of development, education about the knowledge of cosmetics for the aged is necessary.

\subsection{Enriched services}

One major problem that haunts the old age market is that we tend to regard the old persons as a whole, and there is no differentiation between the old and the middle-aged in provision of services. There is a shortage of specific services for the aged, and the large potential of the market for the aged has not been recognized.

Enriched services first refer to enriched content of services. The service providers should design more diverse products and programs for the aged instead of obsessing with health products; new forms of services like old-age entertainment, old-age travelling, old-age education and training programs may also enjoy a good prospect. Enriching the service modes is another aspect of enriched services. Service providers can apply the promotion stunts that are popular among the young to the old-age market and may achieve good results.

\subsection{Convenient services}

Convenient services refer to services that are easily accessible, learnable, and realizable for the aged. Adapting to new consumption modes and venues takes time, and the aged tend to develop fixed consumption habits and reliance on specific products or services.

Lahos elders, despite their ability to learn, are still old persons who may be reluctant to accept new things. Thus, consumption behaviors of Lahos elders principally happen on mobile apps, which are easy to learn and operate. Home delivery services dovetail with their needs, and thus the delivery service of Jingdong (an e-commerce platform) has won popularity among the Lahos elders.

To provide convenient services for the old entails indepth ,enterprise must analysis of their actual needs. For instance, the aged value the nutrition of their meals instead of the price; they like small packages because they do not eat much and they value diversity more than quantity; they love buy ready-to-eat or half-cooked food that only needs heating back home.

Lahos elders account for a major force of consumers among the aged population. A report "potential value of the aging society in China”, released by Wavemaker2020 states that the Lahos elders are energetic and love to explore the world; they play an active role in their family and the society, active online, and have become a major group of consumers online; they have the power to consume, the desire, the decision-making capacity to consume as well as financial intelligence [6]. They have already become a new engine for economic growth and businesses should divide them into different groups and provide more specific products or services.

\section{ACKNOWLEDGMENT}

Research on innovation of community smart business Service Model based on sharing Economy concept, Item no. DZ2019CXJJ07 (Dalian Vocational and Technical College Research and innovation Fund projects)

\section{REFERENCES}

1. China Population 2020: Challenges posed by fewer children and an aging society, https://finance.sina.com.cn/china/gnc,Dem-2020

2. Han Bingzhi: Upgrading of the market for the silver-haired Economic Daily,Apr- 2019

3. Insights: What's the new trend/ opportunity in the market for the aged in China? ,AgeClub. https://www.ageclub.net/activity/2847.html,Aug-2019

4. The 4th sampling investigation of living conditions of the aged in rural and urban areas in China - Empty nesters account for half of the aged population, People.cn,http://world.people.com.cn/n1/2016/1010/c5750 6-28765437.html,Oct-2016

5. Wang Wenzheng. Lahos elders leading a new trend of consumption, People.cn, http://finance.people.com.cn/n1/2019/1023/c100431414816.html,Oct-2019

6. Potential value of the aging society of China.,Soho.com. https://www.sohu.com/a/349627565_99958508,Oct-2019 